\title{
Study of functional parameters of a conveyor by modeling and simulation
}

\author{
Florin Blaga ${ }^{1, *}$, and Iulian Stanasel ${ }^{1}$ \\ ${ }^{1}$ University of Oradea, Industrial Engineering Department, Universității 1, Oradea, Romania
}

\begin{abstract}
The transfer systems conveyor type are an important component of the modern manufacturing systems. Designing and constructing a conveyor involves evaluating its performance for the adoption of the most effective constructive solutions. The paper shows how modelling and simulation can be used in assessing the performance of a conveyor. The studied parameters refer to the kinematic characteristics (the speed of the conveyor) and to the functional indicators of the system components (input rate, service rate).
\end{abstract}

\section{Introduction}

The conveyors are transfer systems which are used to carry different products in successive steps up to the point of destination. Also, with the aid of conveyors is ensured buffer volumes of products to balance the flow when it is necessary [1]. The study of the performance of these systems through modelling and simulation is the subject of several researches.

In [2] is presented a method for designing the driveshaft of a monorail conveyor, using CAD-CAE applications.

In paper [3] a model comparison approach based on material flow systems is investigated That is divided into a microscopic and a macroscopic model scale.

The paper [4] studying existing conveyor system and optimize the critical parts like: Roller, shafts, c-channels for chassis and support, to minimize the overall weight of assembly and material saving.

An applicable scheme for production design in manufacturing, and provides a valuable tool to conclusively obtain the optimal profit of a given production quantity for operations research engineers in today's manufacturing with profound insight is presented in [5].

This paper highlights how modeling and simulation have been used to improve the solutions adopted in the implementation of a transfer system (of) conveyor-type.

\section{Modeling the conveyor using the Taylor ED program}

Figure 1 shows the model of the transport system conveyor-type developed in the Taylor ED program. The conveyor is composed of four sections: 4 and 6 are linear segments, 5 and 7 are circular segments. Also in Figure 1 are shown the other components of the system in which the conveyor is integrated. Thus, the following "atoms" (name specific to the TaylorED program) are highlighted:
1- Product; 2- Bringing installation (source); 3, 8 Operators; 9 - The Team Block is specific to Taylor ED (it interconnects the operators); 10- Exhaust system.

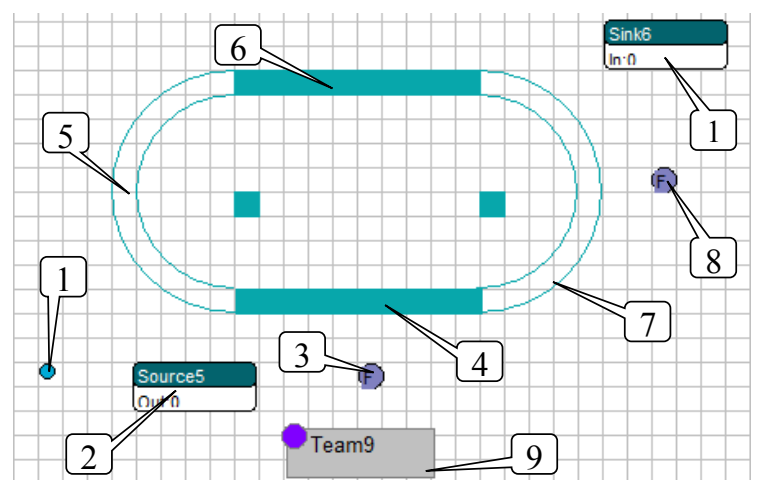

Fig. 1. The model of the conveyor system

In Figure 2 are highlighted the connections between the components of the model. These connections are established between the output ports and the input ports of the elements (atoms) of the model.

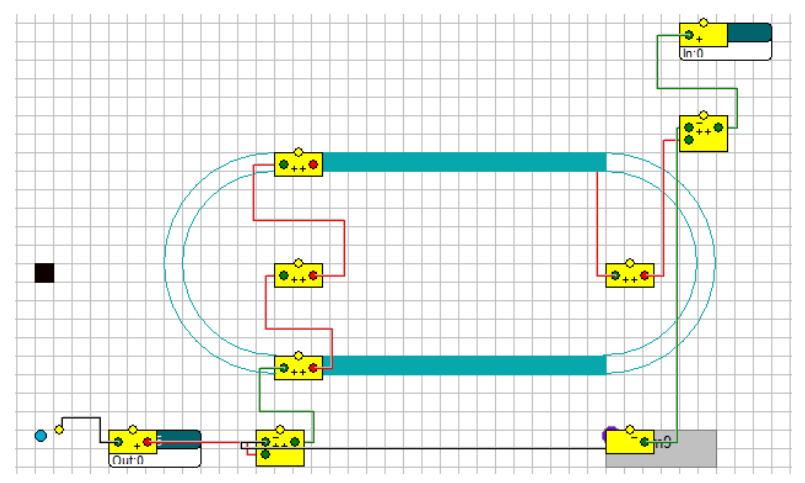

Fig. 2. The model of the system with the connections between atoms.

For each component of the model are made the settings which correspond with to the characteristics of the real system. Thus, in the case of the bringing

* Corresponding author: fblaga@uoradea.ro 
installation (source), is set the time interval between two successive inputs. In the first variant, the interval between two successive entries is considered to be a deterministic parameter with a value of 60 seconds (1 minute) (Fig. 3).

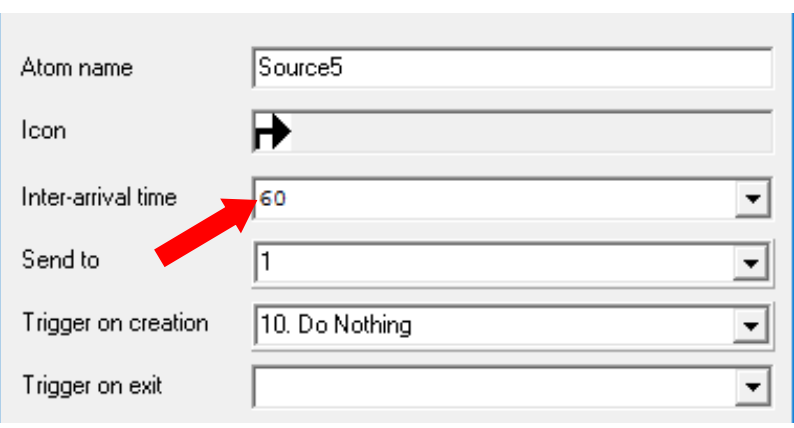

Fig. 4. Setting Inter-arrival time. Variant 1.

The parameters (capacity, length, speed) of the linear sections of the conveyor are shown in Figure 6. In Figure 7 is shown the window setting of specific parameters of the circular sections of the conveyor (speed, radius).

The seeted speed is proportional to the real speed

$$
\text { Speed }_{\text {model }}=5 * \text { Speed }_{\text {real system }}
$$

Speed multiplication was required because in the model also the distances are five times higher compared to the real system.

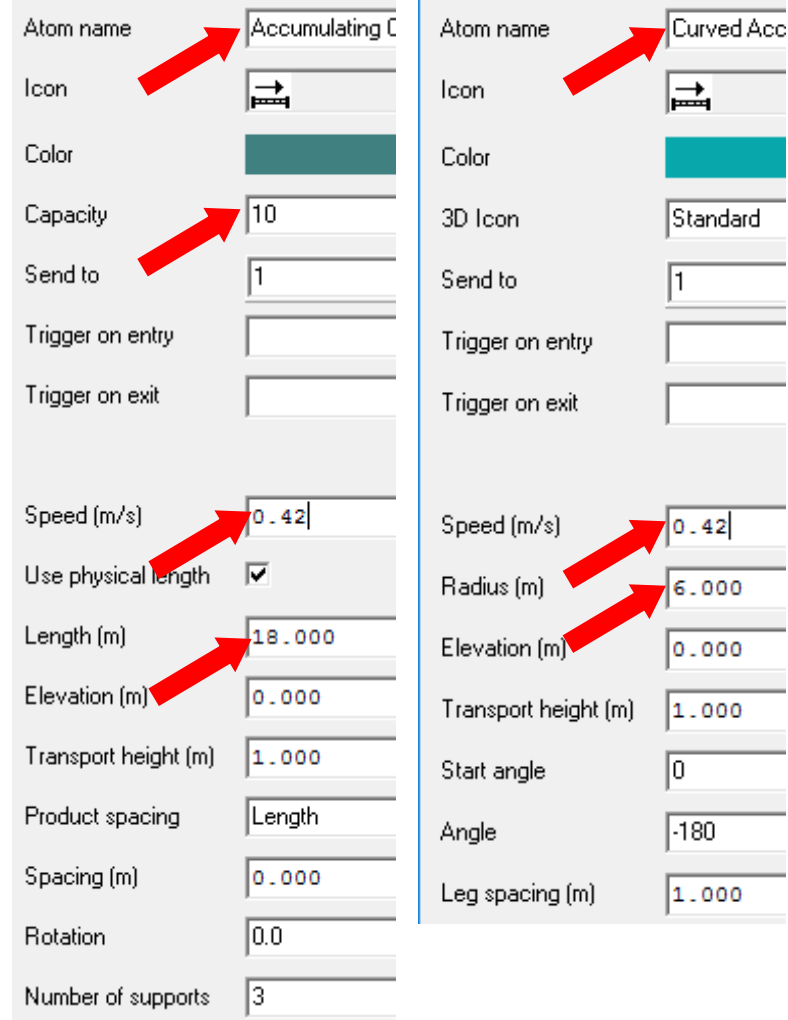

Fig. 5. Setting the parameters of the linear sections and circular of the conveyor. Variant 1

\section{Simulation of conveyor system operation}

To simulate the operation of the conveyor system, a few adjustments must be done in the main menu - Simulate.

The reference interval of time for the simulation Set Stop Time- 8 hours (Fig. 6). Will be recorded information relating to all the components of the model History- All on) on the reference interval of time for which the simulation is done (Fig. 6). To start the simulation is enable the option Reset + Run until Stoptime (Fig. 6).
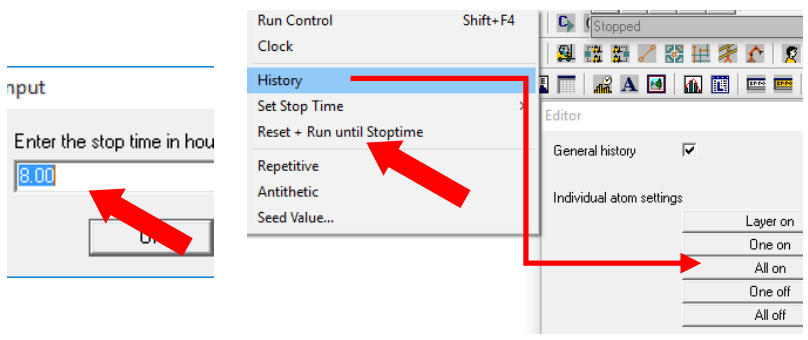

Fig. 6. Setting the reference time and the option to record data

After the simulation, it is generated a summary report which shows the performance of the system components. This report is shown in Figure 7. It may be observed that the system has entered 480 parts and was evacuated 472 parts. The report also shows how many parts there are in each component of the system when the simulation is finished.

For example, on the first linear segment there is a part. Another information refers to the average number of parts, (considering the reference time 8 hours) which can be found on a specific component of the system. Thus, the average number of parts on the first curved section of the conveyor is 3.442 .

\section{summary report}

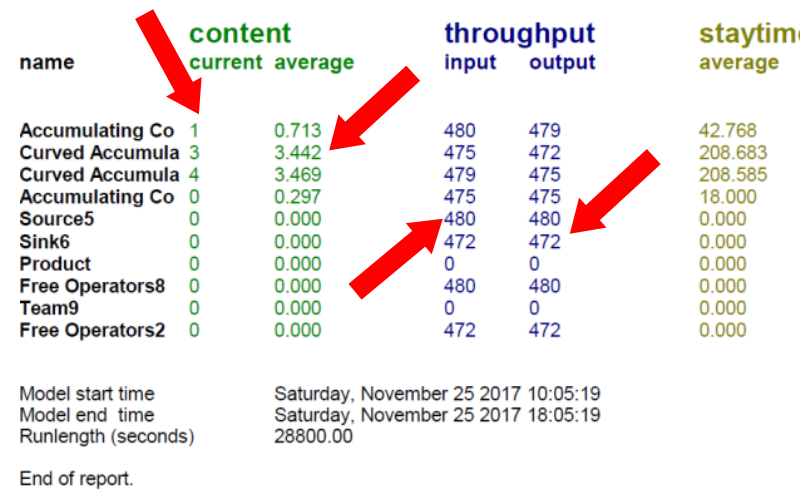

Fig. 7. Summary report of the simulation. Varinat 1

In addition to the synthetic report, the Taylor ED program provides detailed information about each component of the system. Thus, in Figure 8 is shown the filling degree of the source (Status overview). It was busy in the proportion of $100 \%$. 


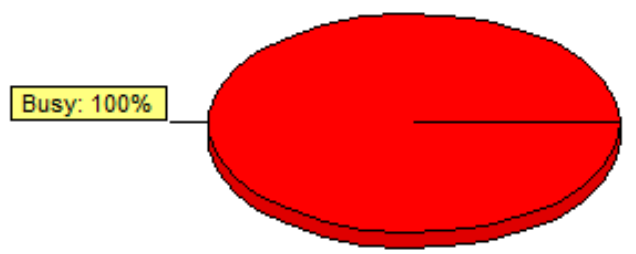

Fig. 8. The degree of loading of the source. Varinat 1

Figure 9 shows the time progress of the number of parts in the waiting string of the first curved segment. So in this string are found, alternatively, 3 or 4 pieces.

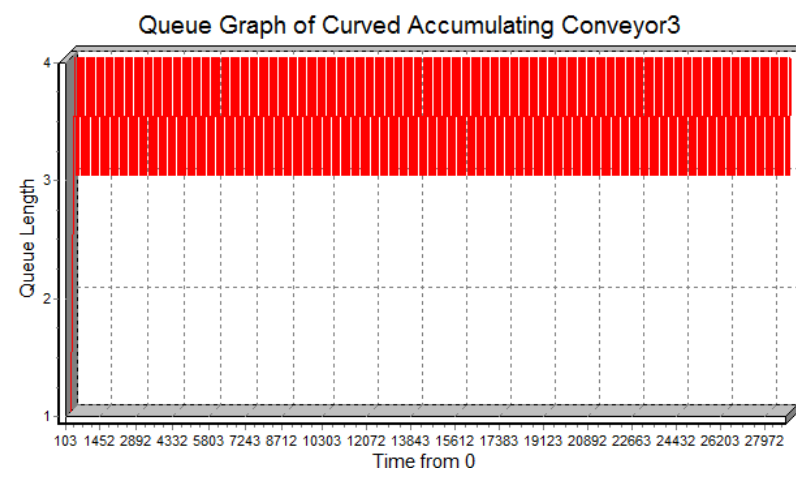

Fig. 9. The evolution in time of the number of parts in the waiting string of the first curb segment

The built model allows simulation taking into account other functional parameters. Thus, if it is considered the time interval between two entries in the system, for a random variable it can be assigned a probability function of the negative exponential type. (Fig.10). The average value for the time interval between two successive inputs is 30 seconds.

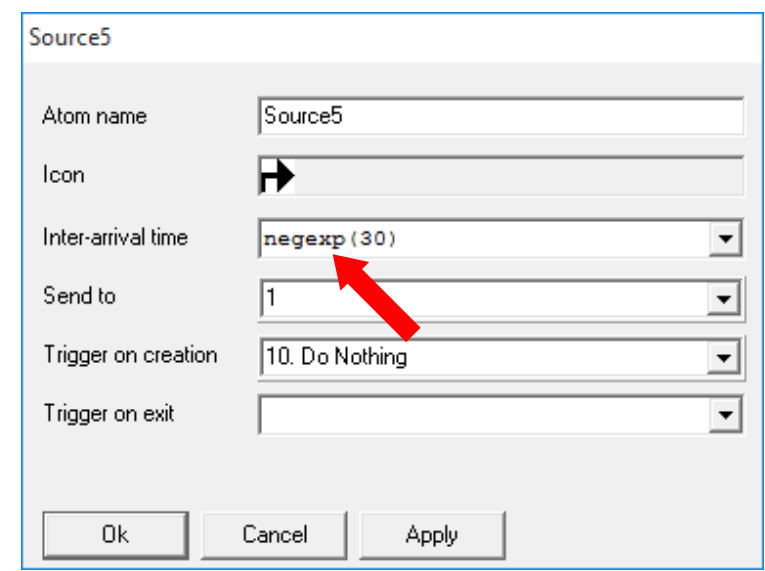

Fig. 10. The Setting of random entries

In figure 11 are presented the results of the simulation shown in the summary report. Thus, have entered in the system 984 parts and 982 come out.

The average time that a part spends on the different sections of the conveyor varies between 31,032 seconds (linear segment) and 32,499 seconds (curve section) (Fig.11)

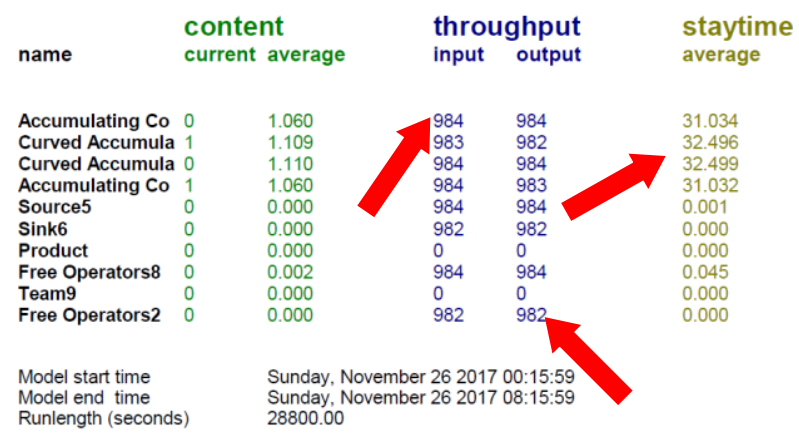

Fig. 11. Summary report of the simulation. Variant 2

Figure 12 shows the histogram of the waiting string corresponding to the first linear segment of the conveyor. It is highlighted that the waiting string contains $0,1,2,3$, 4,5 pieces at different intervals of time.

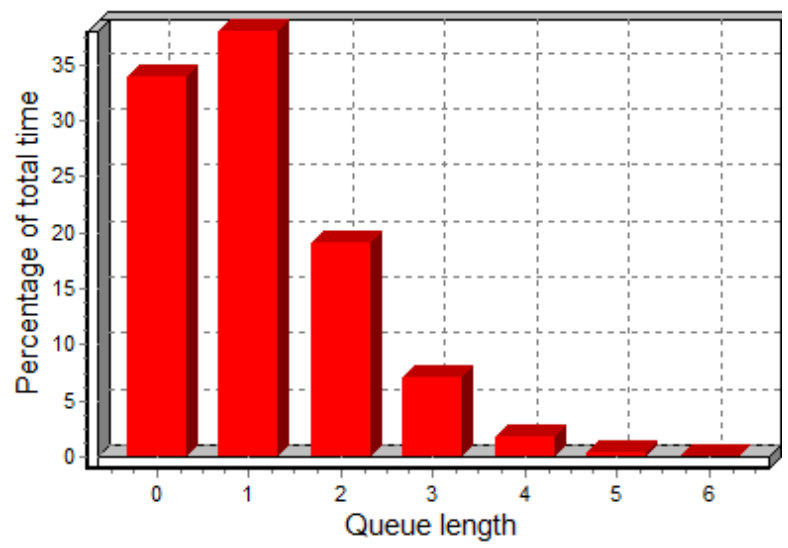

Fig. 12. The histogram of the waiting string corresponding to the first linear segment of the conveyor.

The variation of the number of parts on the second circular segment is shown in Figure 13.

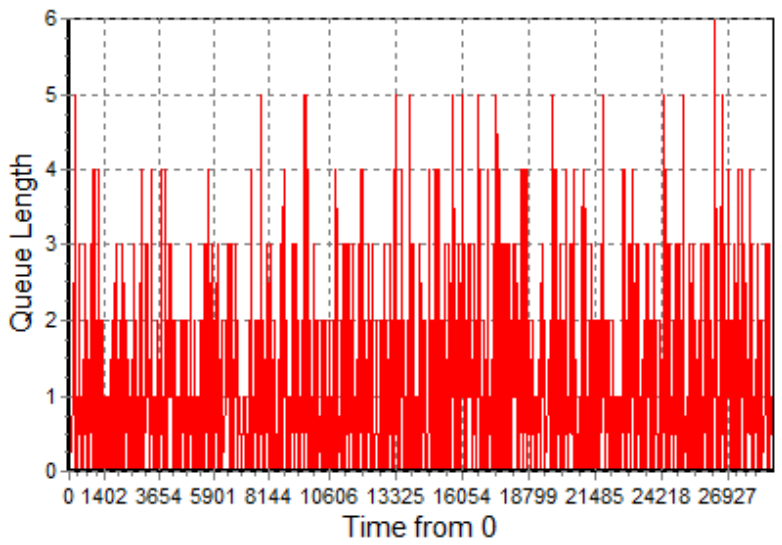

Fig. 13. The variation of the number of parts on the second circular section.

\section{The integration of the transfer system conveyor type into a complex manufacturing system}

The transfer system of conveyor type can be integrated into a complex manufacturing system (Figure 14) with two machines tools (servers) (positions 11 and 14) and 
two linear conveyors (12 and 13). In Figure 20 are presented the components of manufacturing system interconnected between them.

In the case of this model time of processing have random sizes. The function of the probability is negative exponential type [6] expressed by:

$$
f(t)=\beta e^{-\beta t}
$$

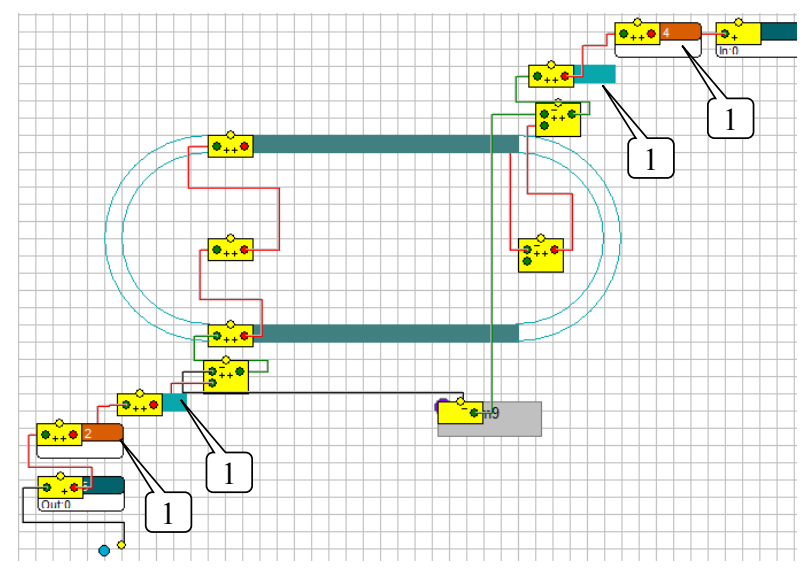

Fig. 14. The transfer system conveyor type integrated into a complex manufacturing system.

In figure 15 is presented the synthetic report. It highlights the fact that 685 parts have been entered into the system and 677 were evacuated.

\begin{tabular}{|c|c|c|c|c|}
\hline name & $\begin{array}{l}\text { content } \\
\text { current average }\end{array}$ & \multicolumn{2}{|c|}{$\begin{array}{l}\text { throughput } \\
\text { input output }\end{array}$} & $\begin{array}{l}\text { staytime } \\
\text { average }\end{array}$ \\
\hline $\begin{array}{l}\text { Accumulating Co } \\
\text { Curved Accumula } \\
\text { Curved Accumula } \\
\text { Accumulating Co } \\
\text { Source5 } \\
\text { Sink6 } \\
\text { Product } \\
\text { Free Operators8 } \\
\text { Team9 } \\
\text { Free Operators2 } \\
\text { Accumulating Co } \\
\text { Server12 } \\
\text { Accumulating Co } \\
\text { Server14 }\end{array}$ & $\begin{array}{l}0.737 \\
0.958 \\
0.770 \\
0.734 \\
0.307 \\
0.000 \\
0.000 \\
0.000 \\
0.000 \\
0.152 \\
0.095 \\
0.617 \\
2.068 \\
0.809\end{array}$ & $\begin{array}{l}684 \\
681 \\
683 \\
682 \\
685 \\
677 \\
0 \\
684 \\
0 \\
679 \\
684 \\
685 \\
679 \\
678 \\
\end{array}$ & $\begin{array}{l}683 \\
679 \\
682 \\
681 \\
685 \\
677 \\
0 \\
684 \\
0 \\
679 \\
684 \\
684 \\
678 \\
677\end{array}$ & $\begin{array}{l}31.033 \\
40.528 \\
32.453 \\
31.012 \\
12.893 \\
0.000 \\
0.000 \\
0.018 \\
0.000 \\
6.466 \\
4.000 \\
25.924 \\
87.696 \\
34.383\end{array}$ \\
\hline $\begin{array}{l}\text { Model start time } \\
\text { Model end time } \\
\text { Runlength (seconds) }\end{array}$ & $\begin{array}{l}\text { Sunday, } \\
\text { Monday, } \\
28800.00\end{array}$ & 2620 & $\begin{array}{l}18: 37: 19 \\
02: 37: 19\end{array}$ & \\
\hline
\end{tabular}

Fig. 15. Summary report of the simulation. Variant 3.

The Taylor ED program provides information on the performance parameters of the system components. Thus, Figure 16 shows the occupancy degree of the machine 1 . It is found that the machine processes $62 \%$ of the reference time interval ( 8 hours).

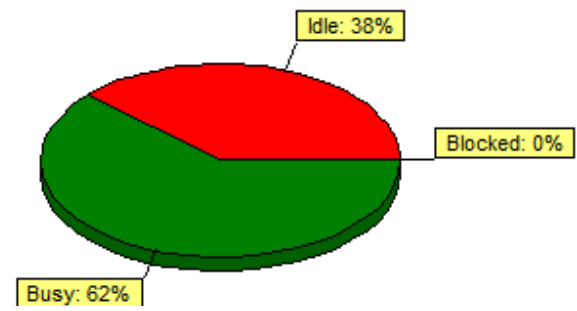

Fig. 16. The degree of loading of the machine 1 (position 11).
Figure 17 highlights the histogram of the first linear section of the conveyor. Thus, $37 \%$ of the time on this section there is only one part into the string, $15 \%$ of the time they are two machines and there are three parts in $2.5 \%$ the reference time.

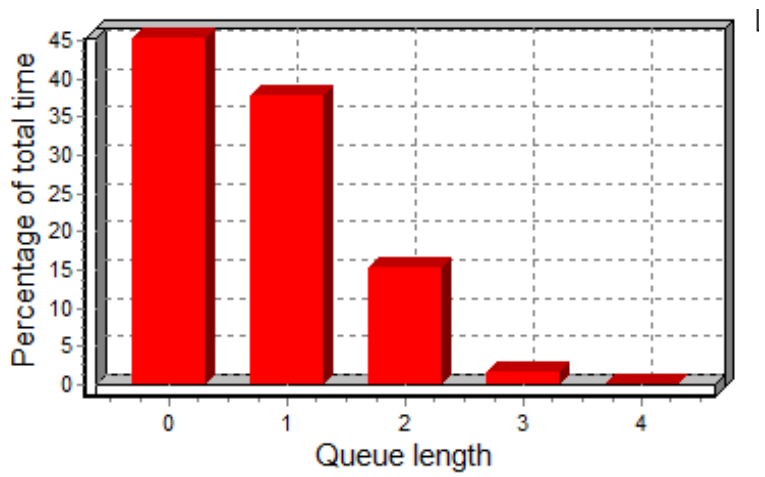

Fig. 17. The histogram of the first linear section of the conveyor.

\section{Conclusions}

Modeling and simulation are appropriate tools for evaluating the performance indicators of manufacturing systems and their components. In the case of the conveyor system, the Taylor ED program allows obtaining detailed information about the components of the manufacturing system in which the conveyor is integrated. Through simulation, the model allows the evaluation of the operation of the conveyor with different sets of data, so that the decision making factor has information to optimize the system form the constructive design and functional point of view.

\section{References}

1. M. Hapenciuc, Transport equipment in the food industry (in romanian) (Ed. Fundaţiei Universitare "DUNĂREA DE JOS" Galaţi, 2004)

2. I. Stănășel, F. Blaga, D. Crăciun, C. Bungău, T. Buidoş, AN. UO. FMTE, 3, 27 (2016)

3. S. Göttlich, S. P. Schindler, V. Schleper, A. Verl, Apl. Math. Mod. 38, 3295 (2014)

4. S. M. Shinde, R.B. Patil, Int. J. Emer. Techno., 3 (1): 168, (2012)

5. Chun-Hsiung Lan, Int. J. of Adv. Man. Techno. 22 (7), 510, (2003)

6. I. Abrudan, Flexible manufacturing systems. Concepts of design and management (in romanian) (Ed. Dacia, Cluj- Napoca, 1996)

The work is a part of project MANUNET ERA-NET, Contract nr.19/2015 "Monorail conveyor system for automated production lines". 